\title{
Sellado de suelo y planeamiento urbano. Análisis de su relación en la ciudad de Bahía Blanca
}

\author{
Soil sealing and urban planning. Analysis of their relationship in the city of Bahía \\ Blanca
}

\author{
Paula A Zapperi \\ paula.zapperi@uns.edu.ar \\ Consejo Nacional de Investigaciones Científicas y \\ Técnicas- Universidad Nacional del Sur, Argentina
}

\author{
Anabella Montico \\ anabella.montico@gmail.com \\ Universidad Nacional del Sur, Argentina
}

\author{
Eliana Santanafessa \\ esantanafessa@gmail.com \\ Universidad Nacional del Sur, Argentina
}

Recepción: 04 Mayo 2020

Aprobación: 07 Julio 2020

Publicación: 02 Noviembre 2020

Cita sugerida: Zapperi, P. A., Montico, A. y

Santanafessa, E. (2020). Sellado de suelo y

planeamiento urbano. Análisis de su relación en la

ciudad de Bahía Blanca. Geograficando, 16(2), e075.

https://doi.org/10.24215/2346898Xe075
Resumen: El objetivo del trabajo es determinar el porcentaje de sellado urbano en distintos sectores de la ciudad de Bahía Blanca. Además, se analizan sus variaciones en función de determinados indicadores urbanísticos. Para ello, se clasificó la cobertura del suelo a través de la fotointerpretación de imágenes satelitales de siete sectores de la ciudad. El criterio de selección se apoyó en la zonificación establecida por el Código de Planeamiento Urbano conjuntamente con el Factor de Ocupación del Suelo. Se destaca el área correspondiente a la zona central, donde el $94 \%$ de la superficie digitalizada se encuentra sellada. En contraposición, los barrios localizados en áreas de crecimiento presentan un porcentaje menor al 50\%. Se pudo advertir la existencia de zonas que demandan un tratamiento urbanístico orientado a compensar la pérdida de suelo natural y prevenir así la degradación del ambiente urbano.

Palabras clave: Suelo sellado, Superficie impermeable, Fotointerpretación, Sistemas de Información Geográfica, Planeamiento urbano.

Abstract: The aim of this study is to determine the percentage of urban sealing in different areas of the city of Bahía Blanca.In addition, its variations are analyzed considering certain urban indicators. To this end, land cover was classified by photointerpretation of satellite images in seven city areas. To this end, land cover was classified by photointerpretation of satellite images in seven city areas. The central area, where $94 \%$ of the digitized surface is sealed, stands out.In contrast, neighborhoods located in growth areas show less than a $50 \%$ of sealing. The existence of areas requiring urban treatment aimed at compensating for the loss of natural soil, thus preventing degradation of the urban environment, was noticeable.

Keywords: Soil sealing, Impermeable surface, Photointerpretation, Geographic Information Systems, Urban planning. 


\section{INTRODUCCIÓN}

En los últimos años el concepto de sellado de suelo ha ampliado su campo de aplicación para pasar a referirse no sólo a un proceso físico de degradación del suelo (Food and Agriculture Organization (FAO), 2015) sino también a la pérdida de suelo por impermeabilización antrópica. Si bien el sellado de suelos urbanos no conlleva necesariamente la pérdida de tierra fértil, se dan modificaciones sobre los ciclos biogeoquímicos e hidrológico. En el ámbito rural, el sellado del suelo constituye un proceso intermedio entre la compactación (producida por pisoteo o paso de maquinaria sobre un suelo natural) y el encostramiento. Estos suelos degradados por sellado serían todavía reversibles. Sin embargo, el sellado que se produce con las edificaciones impermeabiliza el suelo y su pérdida es prácticamente irreversible (García Alvarado, García Rodríguez y Pérez González, 2018). Con el sellado artificial del edafosistema, éste pierde su carácter multifuncional y se convierte exclusivamente en soporte de las actividades relacionadas con los procesos de urbanización, industrialización y la implantación de infraestructuras y equipamientos vinculados a ellos(Valera Lozano, Añó Vidal y Sánchez Díaz, 2011).

En este sentido, el conocimiento de las tasas de crecimiento de superficies artificiales se vuelve fundamental para establecer medidas de control y recuperación (De Tomás, Salas, Santos, Garzón y Moreno, 2010).En el año 2002 la Unión Europea hizo pública su estrategia temática para la protección del suelo y en los informes publicados una década más tarde el sellado es presentado como la principal causa de degradación de suelos (López y Delgado, 2018). El empleo de distintas tecnologías de información geográfica para el cálculo del avance del sellado del suelo es una línea de trabajo que se extiende en el marco de los estudios de sustentabilidad urbana y servicios ecosistémicos urbanos. Distintos autores han estudiado este proceso en ciudades del mundo. Strohbach et al. (2019)compararon planes de desarrollo de áreas residenciales de baja densidad de Alemania con la situación real respecto del sellado antropogénico del suelo a partir de ortofotografías. También analizaron sus influencias sobre el balance hídrico. Hallaron un incremento relativo de entre 8 y $56 \%$ de la superficie impermeable, comparando lo propuesto por los planes y el estado real en el territorio. El estudio de García Alvarado, García Rodríguez y Pérez González (2018) constituye otro antecedente de análisis de este fenómeno. Los autores analizaron la pérdida de suelo por sellado en la Comunidad Autónoma de Madrid mediante la evaluación de imágenes de satélite, fotografías aéreas, cartografía temática digital y planos del catastro. En la Argentina puede mencionarse el estudio realizado por Flores (2018), que identificó para localidades del norte de la provincia de Buenos Aires áreas impermeables y calculó su dimensión fractal como indicador de compactación.

\section{Avance de la urbanización y Sellado del Suelo en Bahía Blanca}

La ciudad de Bahía Blanca se encuentra en el suroeste de provincia de Buenos Aires y está situada a $5 \mathrm{~km}$ de la costa (Figura 1). Es cabecera del partido homónimo, donde se encuentran las localidades de Ingeniero White, General Daniel Cerri y Cabildo. El área de este distrito es de $2.300 \mathrm{~km} 2$ y tiene una población de 301.572 habitantes (Instituto Nacional de Estadística y Censos(INDEC), 2010). Se encuentra latitudinalmente comprendida en la gran franja de climas templados (Capelli de Steffens, Piccolo y Campo de Ferreras, 2005) y la temperatura media anual es de $15,5^{\circ} \mathrm{C}$ con una marcada estacionalidad térmica (Ferrelli, 2017). La precipitación media anual para el período registrado entre 1960 y 2014 fue de $644,6 \mathrm{~mm}$, con variaciones interanuales que van desde $354,7 \mathrm{~mm}$ a $1083,6 \mathrm{~mm}$ (Ferrelli 2016). Esta variabilidad se relaciona principalmente con el fenómeno El Nio Sur Oscilación (ENOS) (Aliaga, Ferrelli y Piccolo, 2017). La ciudad se emplaza en la cuenca inferior del arroyo Napostá Grande, curso de agua que tiene sus nacientes en el Sistema Serrano de Ventania (Carrica, 1998). Existe un gradiente altitudinal de $70 \mathrm{~m}$, aproximadamente, entre el norte de la ciudad, donde se ubican las mayores elevaciones $(70-80 \mathrm{~m})$, y el sector sur, cercano al área costera. 
El crecimiento de la ciudad de Bahía Blanca se enmarca en el proceso de transformación de los patrones de asentamiento urbano de las últimas décadas, caracterizado por un significativo desarrollo de las ciudades intermedias. En la mayoría de las ciudades de este tipo se presentan problemáticas como el crecimiento discontinuo, una baja densidad poblacional y presencia de vacíos urbanos, dotación de áreas verdes y espacio público, y deficiente estructura vial (Terraza, Rubio Blanco y Vera, 2016). En la ciudad de Bahía Blanca el proceso de extensión de la superficie urbana se ha producido de manera discontinua y en baja densidad. Mientras la expansión de la ciudad ha traspasado el Anillo de Circunvalación Externa, en el interior de este limite artificial permanecen importantes superficies de tierras sin ocupar que interrumpen la mancha urbana (Urriza, 2018). En el período 2001-2017, se dio la combinación de un bajo nivel de crecimiento poblacional con una importante expansión del área urbana. La comparación de datos censales muestra una fuerte diferencia entre la velocidad de crecimiento de la población y la del área urbana, situación que se acelera en los últimos años (Centro de Implementación de Políticas Públicas para la Equidad y el Crecimiento (CIPPEC), 2017). Entre 1991 y 2010, la superficie urbana ocupada se incrementó un 89\%, mientras la población creció un $12 \%$. También se aprecia un marcado descenso de la densidad promedio en la ciudad, de 76 hab/ha en el año 1991 a 45 hab/ha en 2010. Simultáneamente, Bahía Blanca ha experimentado un importante proceso de verticalización a partir de la construcción de un gran número de edificios en el área central. De esta manera, se verificaría un doble proceso de expansión urbana: uno vertical, dado por el crecimiento en altura en el centro, propio de la ciudad compacta, y otro horizontal, mediante la extensión en baja densidad en la periferia (Urriza, 2018).

Estas transformaciones implican un cambio en la cobertura del suelo que se manifiesta principalmente en el aumento de las superficies impermeabilizadas, lo que impacta en los procesos y funciones ligadas al ciclo hidrológico. La ocupación del suelo en el medio urbano no responde únicamente a la construcción sino también a su sellado por impermeabilización. Sin embargo, la normativa vigente en la ciudad no presenta disposiciones que regulen este último proceso (Montico, Zapperi, Zilio y Gil, 2019). El presente trabajo parte de la hipótesis de que un indicador de ocupación que sólo regula la parte constructiva no es eficiente a la hora de limitar el sellado del suelo. En este marco, el objetivo del trabajo es determinar el porcentaje de sellado urbano en distintos sectores de la ciudad de Bahía Blanca. Además, se analizan sus variaciones en función de determinados indicadores urbanísticos.

\section{Metodología}

Si bien existe una multitud de criterios y metodologías para el estudio del sellado de suelo en las ciudades, los Sistemas de Información Geográfica (SIG) son los más utilizados. Asimismo, la elección del método de trabajo se adapta tanto a las necesidades y requerimientos del área de estudio como a la disponibilidad de información. De esta manera, bajo este objetivo de investigación pueden encontrarse estudios generados a partir de técnicas de fotointerpretación en conjunción con teledetección, como también mediante la integración de conjuntos de datos espaciales (López y Delgado, 2018). Cabe aclarar que en la Argentina no existen bases de datos sobre coberturas y usos de suelo a escalas espaciales adecuadas para el análisis en ámbitos urbanos. Es preciso tener en cuenta que, para obtener resultados a nivel municipal y catastral, las escalas de trabajo más idóneas varían desde 1:50.000 hasta 1:5.000. García Alvarado, Pérez González y García Rodríguez (2014) consideran que, sin el conocimiento de las condiciones de sellado con elevado nivel de detalle espacial, las intervenciones que pudieran elaborarse serían muy generales.

Para el caso del presente trabajo, la clasificación de la cobertura del suelo se realizó a través de fotointerpretación de imágenes satelitales. En primer lugar, se vectorizóla zonificación definida por el Código de Planeamiento Urbano (Municipalidad de Bahía Blanca, 1993) y sus sucesivas modificaciones. Como parte de los atributos asignados a cada categoría de zonificación se incorporaron los valores de indicadores urbanísticos, como el Factor de Ocupación del Suelo (FOS), que hace referencia al porcentaje de la superficie 
total del terreno que se puede ocupar con los usos establecidos, y el Factor de Ocupación Total (FOT), que es el número que, multiplicado por la superficie total de la parcela, determina la superficie cubierta útil edificable. También se tuvo en cuenta el Centro Libre de Manzana (CLM), que es el espacio central de una manzana delimitado por los planos verticales que pasan por las líneas de frente interno. Asimismo, se consideraron los retiros, que son definidos como líneas que delimitan el área edificable de la parcela y que en el frente coinciden con la línea municipal.

El criterio para la selección de áreas se apoyó en las distintas zonificaciones del Código de Planeamiento Urbano conjuntamente con el FOS establecido para cada una de ellas. Sin embargo, es de destacar que, tal como se presenta en la Figura 1, el valor de este indicador es de 60 en casi toda la ciudad. Para la clasificación del tipo de cobertura, se seleccionaron siete grupos de cuatro manzanas correspondientes a distintas zonificaciones. Este proceso de digitalización respetó los límites determinados por la línea municipal de edificación, por lo que no fueron consideradas las superficies correspondientes a las veredas.

\section{FIGURA 1}

Sectores de análisis y distribución del valor del FOS en la ciudad de Bahía Blanca

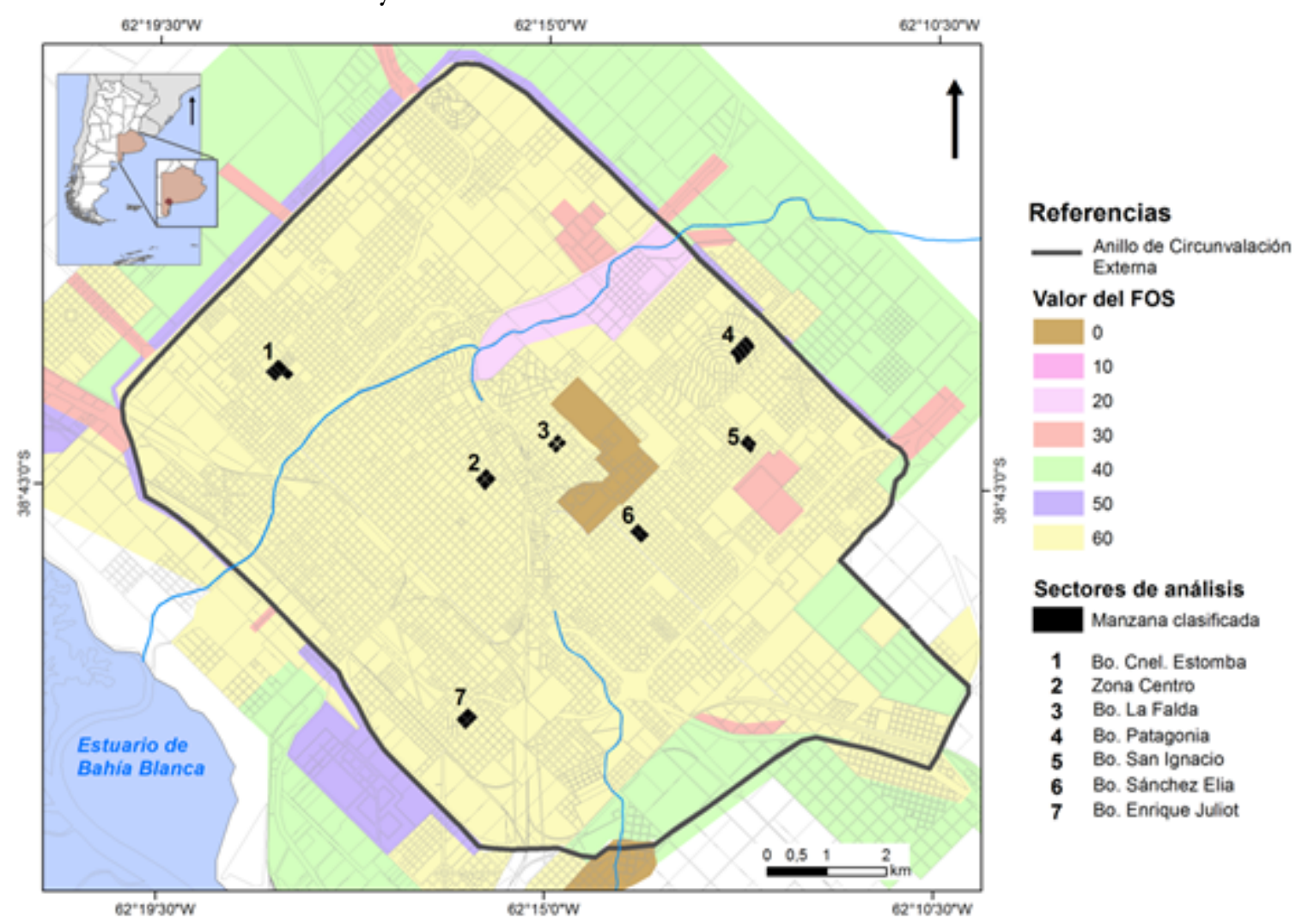

Fuente: Elaboración propia sobre la base de información vectorial del IGN y Código de Planeamiento Urbano, Municipalidad de la Ciudad de Bahía Blanca

En la Tabla 1 se muestran los criterios que guiaron las clasificaciones mencionadas. Estas categorías fueron determinadas a partir de las descripciones de los usos del suelo de Chow, Maidmenty Mays (1994), aplicados a la determinación de la escorrentía superficial, y también por las categorías del proyecto CORINE Land Cover del Programa Copernicus de la Agencia Europea de Medio Ambiente (COPERNICUS, 2020).Los distintos tipos de cobertura fueron vectorizados y llevados a formato de polígono sobre la base de imágenes satelitales obtenidas con el software Google EarthPro. Se trabajó con un nivel de resolución de $1 \mathrm{~m}$ y con el sistema de referencia geográfica POSGAR07. 
TABLA 1

Tipologías de cobertura de la superficie para la clasificación según sellado

\begin{tabular}{|c|c|c|}
\hline Tipo de superficie según sellado & Tipo de cobertura de la superficie & $\begin{array}{c}\text { Descripción del } \\
\text { tipo de cobertura }\end{array}$ \\
\hline Superficie no sellada & Suelo desnudo & Patios y jardines sin vegetación \\
\cline { 2 - 3 } & Vegetación & Patios y jardines con vegetación \\
\hline Superficie sellada & Materiales impermeables & Pisos y solados \\
\cline { 2 - 3 } & & Techos \\
\hline
\end{tabular}

Fuente: Elaboración propia

\section{Resultados Y Discusión}

En la Figura 2 se presentan los porcentajes de suelo sellado y no sellado en función del total del área digitalizada para cada sector de análisis. Se destaca el área correspondiente a la zona centro, donde el 94\% de la superficie digitalizada se encuentra sellada. A este valor le siguen aquellos correspondientes a los barrios La Falda (70,5\%) y Sánchez Elías (55,9\%). Cabe mencionar que se trata de barrios tradicionales de la ciudad de Bahía Blanca, cuyo surgimiento data de aproximadamente 100 aos y sobre los cuales se está llevando a cabo un proceso de reconversión iniciado desde hace ya dos décadas. Esto ltimo se desarrolla principalmente en el barrio La Falda, donde prácticamente han desaparecido los terrenos baldíos y a su vez se han incorporado edificaciones en altura (Zapperi, 2008). Por otra parte, se presentan dos casos en los que las superficies con suelo sellado y no sellado ocupan aproximadamente el 50\% de las áreas respectivamente analizadas. Se trata de los barrios Cnel. Estomba y Enrique Julio, cuyos porcentajes de sellado, si bien por su zonificación corresponden a distrito residencial de densidad media alta y distrito residencial mixto (Tabla 2), son cercanos a los que se presentan en morfologías urbanas de densidad baja. Cabe sealar que se trata de barrios desarrollados bajo planes de vivienda, por lo que quedan encuadrados bajo la Ordenanza Municipal N - 16190, que busca garantizar la presencia de arbolado urbano en este tipo de barrios en el marco del programa de forestación y reforestación anual que se lleva a cabo en la ciudad. Asimismo, define la obligatoriedad, para la empresa constructora de este tipo de conjuntos habitacionales, de la proyección y construcción de los recintos para el arbolado urbano de alineación (Benedetti, Duval y Campo, 2013). 
FIGURA 2

Porcentaje de suelo sellado y no sellado para cada barrio analizado

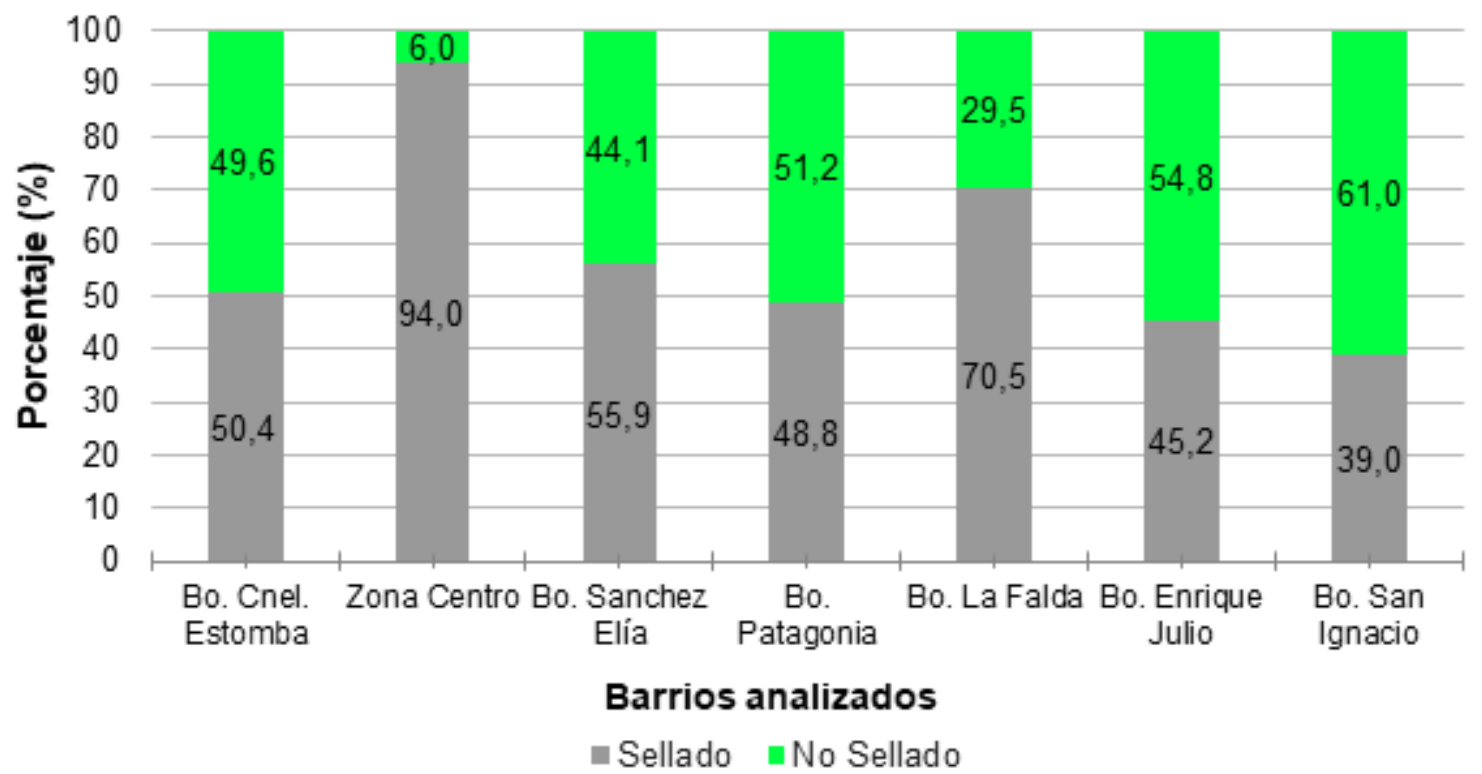

Fuente: Elaboración propia

Los menores porcentajes de suelo sellado se identificaron en los barrios que por su zonificación quedan definidos como de tipo barrio parque (Tabla 2). Se trata del barrio Patagonia, con un porcentaje de sellado del $48,8 \%$, y el barrio San Ignacio, con 39\%. El primer caso constituye una de las contadas excepciones al plano ortogonal que define el parcelamiento en la ciudad de Bahía Blanca (Figura 3). Este barrio surgió en los años 60 como lugar de residencias de fin de semana y vacaciones. En la década del ochenta, por las condiciones del mercado inmobiliario, se convierte en un área atractiva de residencia por disponer de amplios lotes y de presentar un menor precio del suelo (Formiga, 1997). La dotación de servicios y la mejora de la red viaria hacia el sector de su emplazamiento contribuyeron a su crecimiento, el cual se mantiene en la actualidad. Por otra parte, el barrio San Ignacio se creó a partir del año 2000 en un contexto de valorización de aquellos lotes que se promocionaban con servicios y forestación. Por ende, su desarrollo fue promovido por una empresa inmobiliaria que incluyó en su oferta la promoción de un entorno verde y de calidad ambiental y paisajística (Urriza y Garriz, 2014). Cabe señalar que, al tratarse de uno de los últimos barrios que se ha incorporado a la trama urbana, la presencia de lotes vacantes es considerable. Esto último explica en gran parte que en este sector se haya obtenido el mayor porcentaje de suelo no sellado. No obstante, la tendencia identificada en los barrios ya consolidados sugiere que en el barrio San Ignacio el porcentaje de sellado pueda alcanzar al del barrio Patagonia. 
TABLA 2

Zonificación e indicadores urbanísticos definidos para los barrios estudiados

\begin{tabular}{|c|c|c|c|c|c|c|}
\hline $\begin{array}{l}\text { Barrio de } \\
\text { estudio }\end{array}$ & $\begin{array}{c}\text { Zonificación según } \\
\text { CPU }\end{array}$ & FOS & FOT & $\begin{array}{l}\text { Altura } \\
\text { máxima }\end{array}$ & $\begin{array}{l}\text { Centro libre } \\
\text { de manzana } \\
\text { (CLM) }\end{array}$ & $\begin{array}{l}\text { Retiros en función de la } \\
\text { Línea municipal de } \\
\text { edificación }\end{array}$ \\
\hline $\begin{array}{l}\text { Zona } \\
\text { Centro }\end{array}$ & $\begin{array}{l}\text { C1-Area Central- } \\
\text { Microcentro Direccional }\end{array}$ & $60 \%$ & 3 & 15 pisos & $\begin{array}{c}\text { Caso A- } \\
\text { Ocupación } \\
100 \% \text { hasta } 6 \mathrm{~m}\end{array}$ & - \\
\hline $\begin{array}{c}\text { Bo. } \\
\text { Patagonia }\end{array}$ & $\begin{array}{c}\text { RP1(4)- Residencial } \\
\text { parque de densidad baja }\end{array}$ & $60 \%$ & 0,75 & 3 pisos & - & $\begin{array}{l}4 \mathrm{~m} \text { frente } \\
2 \mathrm{~m} \text { bilateral } \\
2 \mathrm{~m} \text { fondo }\end{array}$ \\
\hline $\begin{array}{l}\text { Bo. San } \\
\text { Ignacio }\end{array}$ & $\begin{array}{c}\text { RP2(4)- Residencial } \\
\text { parque de densidad baja }\end{array}$ & $60 \%$ & 0,75 & 3 pisos & - & $\begin{array}{c}3 \mathrm{~m} \text { frente, Unilateral } 2,4 \mathrm{~m} \text { para } \\
\text { lotes mayores de } 12 \mathrm{~m} \text { de frente, } \\
\text { (L-20)/2 fondo (no en esquinas) } \\
\text { con } 50 \% \text { ocupación hasta } 4,5 \mathrm{~m} \\
\text { de altura }\end{array}$ \\
\hline $\begin{array}{l}\text { Bo. La } \\
\text { Falda }\end{array}$ & $\begin{array}{l}\text { R2(4)- Residencial general } \\
\text { de densidad } \\
\text { media/Residencial de } \\
\text { transición }\end{array}$ & $60 \%$ & 1,2 & 3 pisos & $\begin{array}{c}\text { Caso C- } \\
\text { Ocupación } 50 \% \\
\text { hasta } 4,5 \mathrm{~m} \text { de } \\
\text { altura }\end{array}$ & $3 m$ frente \\
\hline $\begin{array}{l}\text { Bo. } \\
\text { Sánchez } \\
\text { Elia }\end{array}$ & $\begin{array}{c}\text { R2(6)- Residencial general } \\
\text { de densidad } \\
\text { media/Residencial de } \\
\text { transición }\end{array}$ & $60 \%$ & 1,2 & 3 pisos & $\begin{array}{l}\text { Caso C- } \\
\text { Ocupación } 50 \% \\
\text { hasta } 4,5 \mathrm{~m} \text { de } \\
\text { altura }\end{array}$ & $3 \mathrm{~m}$ frente \\
\hline $\begin{array}{l}\text { Bo. } \\
\text { Enrique } \\
\text { Julio }\end{array}$ & $\mathrm{RM}(2)$ - Residencial mixto & $60 \%$ & 2,2 & 4 pisos & $\begin{array}{c}\text { Caso C- } \\
\text { Ocupación } 50 \% \\
\text { hasta } 4,5 \mathrm{~m} \text { de } \\
\text { altura }\end{array}$ & - \\
\hline $\begin{array}{l}\text { Bo. Cnel. } \\
\text { Estomba }\end{array}$ & $\begin{array}{l}\text { R1(9)- Residencial general } \\
\text { de densidad media alta }\end{array}$ & $60 \%$ & 1,4 & 4 pisos & $\begin{array}{c}\text { Caso C- } \\
\text { Ocupación } 50 \% \\
\text { hasta } 4,5 \mathrm{~m} \text { de } \\
\text { altura }\end{array}$ & - \\
\hline
\end{tabular}

Fuente: Elaboración propia sobre Código de Planeamiento Urbano, Municipalidad de Bahía Blanca (1993)

Las disposiciones específicas para cada zonificación se conjugan para dar lugar a distintas tramas urbanas, aun teniendo el mismo FOS. Como puede observarse en la Figura 3, la distribución de áreas verdes se identifica principalmente en las áreas centrales de las parcelas, como también acompañando los límites de los lotes. Es así que otro de los aspectos que se desprenden del análisis es la distribución de las superficies permeables en las manzanas según las distintas morfologías. Esto estaría controlado por los parámetros CLM y la disposición de los retiros de frente, fondo o laterales. Se destacan las diferencias entre la morfología residencial de baja densidad y la de media densidad. En el primer caso, como los barrios Patagonia y San Ignacio, donde la normativa no dispone CLM sino de retiros, las áreas no selladas se distribuyen en toda la superficie de la manzana. En contraposición, las morfologías residenciales de densidad media, como Sánchez Elía y La Falda, presentan CLM y las áreas permeables se concentran mayormente en la zona central de las manzanas. 
Por otra parte, en términos de cobertura el tratamiento del frente de cada lote debiera articularse con lo que ocurre en el interior de la manzana. Si bien las veredas y/o aceras no fueron analizadas pues no se incluyen en el cálculo del FOS, es preciso señalar su contribución relativa al sellado del suelo urbano a través de su impermeabilización. Es importante indicar que no existen reglamentaciones referidas a su tratamiento. Aun así, se trata de zonas con potencialidad para su reconversión en función del enverdecimiento y mitigación del sellado. Al momento, existe normativa orientada a la disposición y a las especies que conforman el arbolado de la ciudad. De esta manera, la Ordenanza Municipal N 16859 de Arbolado Urbano y Espacios Verdes reglamenta el tamaño de los recintos donde se plantarán los árboles, como también su disposición. Sin embargo, no existen referencias sobre el tipo de cobertura y tratamiento que deben tenerlos espacios externos a la línea de edificación. Existe una excepción dada por la Ordenanza Municipal No 6855, que establece como Área Particularizada la manzana comprendida entre las calles Panamá, Zapiola, Salta y Santiago del Estero, designada catastralmente como Circunscripción I, Sección B, Manzana 37c. En su artículo tercero, la Ordenanza Municipal No 6855define que el tratamiento de las veredas públicas se efectuará con baldosas en un ancho igual al 50\% de su superficie y el resto de la acera no tratada con solado deberá estar cubierta de césped. De esta manera, el caso de estudio da cuenta de una de las limitaciones más frecuente de las normativas urbanísticas de la Argentina, que ponen mayor énfasis en la regulación del espacio privado omitiendo en gran parte el espacio público. Se trata de una carencia que resulta más crítica en ciudades y aglomerados expuestos a riesgo de inundación.

\section{FIGURA 3}

Distribución de los tipos de cobertura de la superficie en los distritos analizados
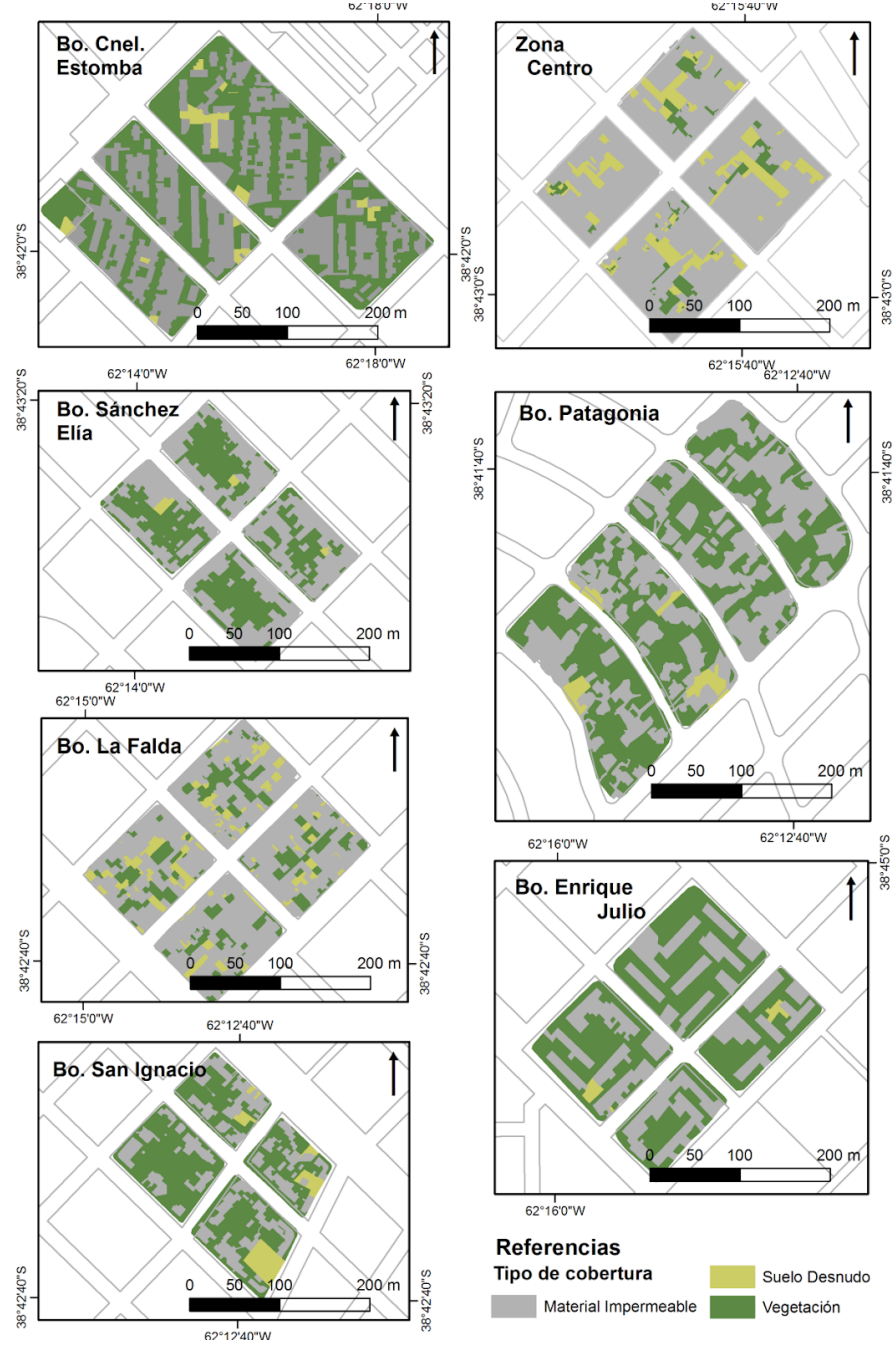

Referencias

\begin{tabular}{c|l} 
Tipo de cobertura & Suelo Desnudo \\
Material Impermeable & Vegetación
\end{tabular}

Fuente: Elaboración propia 
Los resultados muestran que las morfologías residenciales de baja densidad son las que presentan los menores porcentajes de superficie sellada. Sin embargo, son también estas morfologías las que propician el crecimiento de la mancha urbana bajo un modelo disperso. A su vez, la morfología correspondiente al área central de la ciudad presenta un $94 \%$ de superficie sellada. En esta área se identifica un proceso de verticalización, propio de un crecimiento compacto (Urriza, 2018). En este punto, surge el interrogante respecto de las posibilidades de compatibilización de un crecimiento urbano que promueva la reducción del sellado del suelo con un modelo de urbanización compacta. Al respecto, Francesconi Latorre, Martínez Clavijo y Díaz Forero (2014) señalan la importancia de un balance entre la densificación y la disponibilidad de suelos para soportar coberturas que ofrezcan bienes y servicios ecosistémicos. Esto requiere articular instrumentos específicos para la gestión de la cobertura, con indicadores de diseño urbano que involucre la función ambiental en el aprovechamiento urbanístico.

Es interesante la propuesta de García Alvarado, García Rodríguez y Pérez González (2018), que sugieren el porcentaje superficial de sellado por manzana como uno de los criterios fundamentales para calificar la pérdida de suelo en el proceso de crecimiento urbano. En este marco, consideran que hasta un $20 \%$ de suelo sellado en manzana urbana terminada puede asumirse como una forma respetuosa de hacer ciudad. El segundo intervalo, de 20 a 40, todavía puede considerarse tolerable; entre 60 y 80 debería considerarse grave y más del $80 \%$ debería ser clasificado como inasumible, y por ende como mala práctica urbana. Sin duda, todo corte de intervalos tiene sus problemas, pero puede ayudar a valorar el cumplimiento de las directrices específicas de sellado de suelo.

Si se contrastan los valores propuestos como parámetro con aquellos obtenidos en el análisis se puede advertir que el sellado de la zona central de la ciudad se encuadra en lo que los autores consideran una mala práctica urbana. Por otra parte, en el barrio de mayor cercanía a la zona central entre los estudiados (barrio La Falda) el porcentaje de sellado se corresponde con lo que los autores mencionados consideran como grave. De acuerdo con los cálculos realizados, el 60,9\% de la superficie total digitalizada para el sector ha sido ocupada por construcciones techadas. A la vez, un $70 \%$ de esta superficie total se encuentra impermeabilizada. De esta diferencia se desprende que la impermeabilización corresponde aún también a espacios libres que no implican edificación. Por ello, la lo que la pérdida de suelo natural es un proceso cuya regulación no necesariamente estaría alcanzada por un indicador urbanístico como el FOS. Al respecto, cabe mencionar el ejemplo de la Ordenanza Municipal N'8775/2007 emitida por el gobierno de la ciudad de Resistencia, provincia del Chaco. Esta reglamentación, con el objetivo de aminorar el impacto hidrológico de la urbanización, ha establecido el Factor de Impermeabilización de la Superficie (FIS), que determina el grado de impermeabilización del suelo, y el Factor de Impermeabilización de la Superficie (FIT), que determina el grado de impermeabilización total. De esta manera, toda propuesta de edificación deberá estar acompañada de una evaluación hidrológica en la que el pico del hidrograma generado con el FIS y el FIT propuestos no supere el pico del hidrograma con el FIS y el FIT antecedentes. Para ello, deberán preverse, dentro de cada parcela, dispositivos o mecanismos atenuantes del efecto producido por las precipitaciones intensas. Si bien se trata de un avance importante en lo que respecta a medidas que regulen la impermeabilización, para su efectividad también es necesaria una concordancia con los permisos de edificabilidad y los factores de ocupación del suelo (FOS y FOT), que por su parte determinan la posibilidad de mantener la forestación en los centros de las parcelas o la forestación de las aceras (Alcalá, 2012).

\section{ConcLuSIONES}

La definición espacial que requiere el trabajo a escala urbana suele ser un desafío a nivel metodológico. A su vez, la integración con indicadores urbanísticos es fundamental pues contribuye con la aplicación de los 
resultados obtenidos en la generación de instrumentos de gestión y planificación urbana. En esta línea, es fundamental fijar la mirada y los propósitos en la urbanización más allá del hecho edificatorio (García Alvarado, Pérez González y García Rodríguez,2014). Esto implicaría generar estándares urbanísticos que den lugar a procesos mitigadores de la urbanización en zonas de crecimiento y el enverdecimiento en espacios urbanos consolidados pero con un aumento de su densidad poblacional. De esta manera, se direccionan los modelos de desarrollo urbanístico hacia mejores prácticas que minimicen o mitiguen los efectos adversos del sellado (Unión Europea, 2011). En este marco, el monitoreo continuo de los cambios espaciales en las ciudades es primordial para la generación de información que permita la evaluación de los indicadores urbanísticos que regulan cuestiones de sustentabilidad. La falta de base de datos con respecto a usos y coberturas del suelo es realmente un obstáculo. Sin embargo, las geotecnologías permiten salvar esta ausencia. El método empleado permitió el reconocimiento de la superficie sellada en distintas áreas de la ciudad a la vez que se pudo relacionar con los indicadores establecidos. Estos resultados se consideran un avance en términos de datos de referencia que puedan guiar el análisis futuro de imágenes satelitales. Se trata de un procedimiento que permite ampliar el área de estudio y a su vez reducir los tiempos de clasificación.

\section{Agradecimientos}

El trabajo se desarrolló en el marco del PGI Geografía física aplicada al estudio de la interacción sociedadnaturaleza. Problemáticas a diversas escalas temporo-espaciales (24/ZG78), financiado por la SGCyT (UNS). Se agradece el asesoramiento brindado por la Lic. María Verónica Luorno y el Mg. Pablo Forgia, pertenecientes a la Oficina Central Territorial de Datos dependiente de la Dirección General de Catastro y Obras Particulares del Municipio de Bahía Blanca.

\section{REFERENCIAS}

Alcalá, L. (agosto, 2012). Avatares de la manzana. Entre la dispersión y la densificación. En 9a Bienal del Coloquio de Transformaciones Territoriales. Asociación de Universidades del Grupo Montevideo y Universidad Nacional de Tucumán. San Miguel de Tucumán. Recuperado de http://www.augm-cadr.org.ar/archivos/9na-bienal/me sas/MESA\%201/Subtema\%20B/64\%20b.\%20Laura\%20Alcal\%C3\%A1.pdf

Aliaga, V. S., Ferrelli, F. \& Piccolo, M. C. (2017). Regionalization of climate over the Argentine Pampas. International Journal of Climatology, 37(S1), 1237-1247. https://10.1002/joc.5079

Benedetti, G. M., Duval, V. S. y Campo, A. M. (2013). La variable arbórea en la ciudad de Bahía Blanca. Perspectivas en los nuevos barrios populares. Geografia em Questão, 6(2). Recuperado de http://e-revista.unioeste.br/index. $\mathrm{php} /$ geoemquestao/article/view/6745/6356

Capelli de Steffens, A., Piccolo, M. C. y Campo de Ferreras, A. M. (2005). Clima urbano de Babia Blanca. Buenos Aires: Universidad Nacional del Sur. Departamento de Geografía y Turismo.

Carrica, J. (1998). Hidrogeología de la cuenca del arroyo Napostá Grande, Provincia de Buenos Aires (Tesis doctoral inédita), Universidad Nacional del Sur, Departamento de Geología, Bahía Blanca.

Centro de Implementación de Políticas Públicas para la Equidad y el Crecimiento (CIPPEC). (2017). Hacia un plan de desarrollo urbano integral para Babia Blanca. Una propuesta de co-creación de políticas públicas y planificación. Informe elaborado en el marco del Programa de Ciudades de CIPPEC. Buenos Aires: CIPPEC. Recuperado de https://www.cippec.org/wp-content/uploads/2017/09/Hacia-un-plan-de-desarrollo-urbano-integral-paraBahia-Blanca2.pdf

Chow, V. T., Maidment D. R. y Mays, L. W. (1994). Hidrología aplicada. Santa fé de Bogotá: McGraw Hill

COPERNICUS. (2020).Recuperado de https://www.land.copernicus.eu/

De Tomás, A., Salas, F. J., Santos, C., Garzón, A. y Moreno, V. (2010). Estimación del sellado del suelo mediante técnicas de análisis espectral. Serie Geográfica, 16, 81-92. Recuperado de http://hdl.handle.net/10017/14241 
Ferrelli, F. (2016). Análisis del clima local y micro-local de la ciudad de Babia Blanca. (Tesis doctoral inédita). Universidad Nacional del Sur, Departamento de Geografía y Turismo, Bahía Blanca. Recuperado de http://rep ositoriodigital.uns.edu.ar/bitstream/123456789/2698/1/Tesis_Ferrelli_2016.pdf

Ferrelli, F. (2017). Análisis del clima local y micro-local de la ciudad de Bahía Blanca, Argentina. Geográfica Digital, 13(26), 1-6

Flores, A. P. (2018). La fractalidad de las zonas periurbanas. El caso de las zonas periurbanas: el caso de seis municipios de la región metropolitana de Buenos Aires. Teoría Sociourbana, 1(1). Recuperado de https://www.ungs.edu.ar /wp-content/uploads/2018/07/revista-Socio-historia-N\%C2\%BA1.pdf

Formiga, N. (1997). Transformaciones recientes en el espacio periurbano bahiense. Revista Interamericana de Planificación. 114, 119-131.

Francesconi Latorre, R., Martínez Clavijo, I. y Díaz Forero, P. (2014). Bienes y servicios ecosistémicos en la planificación y gestión de áreas urbanas consolidadas. Territorios, 30, 191-218. https://10.12804/territ30.201 4.09

García Alvarado, J. M., García Rodríguez, M. P. y Pérez González, M. E. (2018). Evaluación y medida del sellado de suelos en el Norte de Madrid (España). Boletín de la Asociación de Geógrafos Españoles, 76, 1-19. https://10.21 138/bage. 2513

García Alvarado, J. M., Pérez González, M. E. y García Rodríguez, M. D. P. (2014). Revisión del concepto de sellado de suelos y propuesta de tipología urbana. Anales de Geografía de la Universidad Complutense, 34(1), 87-103). h ttps://10.5209/rev_aguc.2014.v34.n1.45193

López, E. y Delgado, J. (2018). Obtención de la superficie de sellado de suelo a partir del tratamiento e integración de conjuntos de datos espaciales de ocupación del suelo. En A. Nieto Masot y G. Cárdenas Alonso (Eds.), Sistemas de información geográfica y teledetección: aplicaciones en el análisis territorial (pp. 25-38). Recuperado de https:/ /dialnet.unirioja.es/servlet/articulo?codigo $=6634823$

Montico, A., Zapperi, P. A., Zilio, M. I. y Gil, V. (2019). Identificación de servicios ecosistémicos urbanos en la ciudad de Bahía Blanca y su aplicación al análisis de la seguridad hídrica. Revista Estudios Ambientales, 70(1), 56-78. Recuperado de http://www.fch.unicen.edu.ar/ojs-3.1.0/index.php/estudios-ambientales/article/view/415

República Argentina, Instituto Nacional de Estadística y Censos (INDEC).(2010). Censo Nacional de Población, Hogares y Vivienda 2010.Recuperado de https://www.indec.gob.ar/ftp/censos/2010/CuadrosDefinitivos/P2 -D_6_56.pdf

República Argentina, Municipalidad de Bahía Blanca. (1993).Código de Planeamiento Urbano

Strohbach, M. W., Döring, A. O., Möck, M., Sedrez, M., Mumm, O., Schneider, A. K. y Schröder, B. (2019). The "hidden urbanization": trends of impervious surface in lowdensity housing developments and resulting impacts on the water balance. Frontiers in Environmental Science, 7(29). https://10.3389/fenvs.2019.00029

Terraza, H., Rubio Blanco, D. y Vera, F. (2016). De ciudades emergentes a ciudades sostenibles. Santiago de Chile: ARQ. Recuperado de https://publications.iadb.org/handle/11319/8150

Unión Europea. Comisión Europea, Dirección General de Medioambiente.(2011). Overview of best practices for limiting soil sealing or mitigating its effects in EU-27. Informe Final. Bruselas: Unión Europea. Recuperado de https://op.europa.eu/en/publication-detail/-/publication/c20f56d4-acf0-4ca8-ae69-715df4745049

Urriza, G. (junio, 2018). Expansión urbana en ciudades intermedias de crecimiento demográfico bajo: el caso de Bahía Blanca, Argentina. En X Seminario Internacional de Investigación en Urbanismo, Barcelona-Córdoba, Junio 2018. Departament d'Urbanisme i Ordenació del Territori. Universitat Politècnica de Catalunya. Barcelona. Recuperado de http://hdl.handle.net/2117/134596

Urriza, G. y Garriz, E. (2014). ¿Expansión urbana o desarrollo compacto? Estado de situación en una ciudad intermedia: Bahía Blanca, Argentina. Revista Universitaria de Geografia, 23(2), 97-123. Recuperado de http:// bibliotecadigital.uns.edu.ar/pdf/reuge/v23n2/v23n2a03.pdf

Valera Lozano, A., Añó Vidal, C. y Sánchez Díaz, J. (2011). Crecimiento urbano (1956-2005) y sellado antropogénico del suelo en el municipio de Alacant. Serie Geográfica, 17, 97 - 108. Recuperado de http://digital.csic.es/bitstre am/10261/43161/1/CA\%c3\%b1\%c3\%b320.pdf 
Zapperi, P. (2008). Transformaciones en los usos del suelo en la avenida Cabrera en los últimos 12 años y su incidencia en el área circundante (Tesis inédita de licenciatura). Universidad Nacional del Sur, Departamento de Geografía y Turismo, Bahía Blanca. 